\title{
DE NUEVO SOBRE LA CONFIANZA LEGÍTIMA, COMO FORMA DE DECLARACIÓN UNILATERAL DE VOLUNTAD
}

Por Marcelo J. López Mesa

\author{
Académico correspondiente de la Real Academia de Jurisprudencia y \\ Legislación de Galicia - Presidente de la Asociación Iberoamericana de Derecho \\ Privado - Presidente de la Cámara de Apelaciones de Trelew, Argentina - \\ Profesor visitante de las Universidades de Coruña, Coimbra y Perugia
}

Email: mlopezmesa@juschubut.gov.ar

La declaración unilateral de voluntad, en su rol de fuente de las obligaciones, carga desde siempre con una enconada oposición de las concepciones más tradicionales.

Focalizaremos aquí el análisis de la confianza legítima, una de sus especies innominadas y de mayor futuro.

The unilateral declaration of will, in its role as the source of obligations, charge always a bitter opposition from traditional conceptions. 'll Focus here analyzing the legitimate expectations of its unnamed species and greater future.

\section{1) Noción preliminar.}

La declaración unilateral de voluntad, en su rol de fuente de las obligaciones, carga desde siempre con una enconada oposición de las concepciones más tradicionales. Cuando se hizo evidente que ella, en ciertos y determinados casos, era efectivamente una fuente obligacional, la oposición -que antes era franca y hasta enconada-se volvió larvada e indirecta, intentado sus detractores sostener criterios reduccionistas que llevaran a que, en los hechos, se acotara tanto el ámbito de la aplicación de la declaración unilateral, que su imperio fuera equivalente a la nada misma; algo comparable al imperio nominal de Napoleón en la Isla de Elba. 
El caso es que mientras estábamos dedicados a profundizar el estudio de las fuentes de las obligaciones -en general- y de la declaración unilateral de voluntad -en particular-, dimos con una interesante contribución de un jurista mexicano, el Prof. Rafael ROJINA VILLEGAS, que propone dividir las aplicaciones de la declaración unilateral de voluntad en dos grupos diversos ${ }^{1}$ :

A) las formas nominadas de esta idea, que son las que encuentran acogida en alguna norma del ordenamiento legal vigente; ejemplos de ellas son la promesa de recompensa, los títulos al portados, el concurso abierto al público, la estipulación en favor de tercero, etc., las que cualquier obra de obligaciones trata; y

B) las formas innominadas de esta figura, que no están captadas específicamente por norma alguna, pero que pueden aplicarse sin esfuerzo. Dejando de lado las que menciona ROJINA, que se apegan en exceso al ordenamiento mexicano, hemos encontrado algunas formulaciones del derecho moderno que, constituyen derivaciones del principio general de la buena fe, y encajan sin esfuerzo en el molde de la declaración unilateral de la voluntad, entendida como fuente de obligaciones.

Una de estas formas innominadas de aplicación de la voluntad unilateral es la doctrina de los actos propios, en virtud de la cual se obliga a una persona a permanecer atada a la confianza que suscitara en otros con una declaración o actuación suya. Habiendo escrito ya mucho sobre ella, remitimos a elaboraciones nuestras anteriores ${ }^{2}$.

Otra de estas formas innominadas es el principio de la confianza legítima. No se nos había ocurrido esta vinculación, hasta que leímos un párrafo del maestro CASTÁN TOBEÑAS, citando a PUIG BRUTAU que hace la vinculación en estos términos: "Con excelente criterio señala, a tales efectos, Puig Brutau cómo ha de jugar, en el problema de la fuerza vinculante de las declaraciones unilaterales de voluntad, el factor, de índole social, de la protección de la confianza. Lo declarado unilateralmente ... puede haber influido en la conducta ajena, y en la medida en que haya sucedido así, puede ser necesario proteger la confianza depositada en la apariencia. Si la relación jurídica entre

\footnotetext{
${ }^{1}$ ROJINA VILLEGAS, Rafael, "Compendio de Derecho Civil III. Teoría de las obligaciones”, $27^{\text {a }}$ edic., Edit. Porrúa, México, 2007, pp. 212 y ss.

${ }^{2}$ Vid. LÓPEZ MESA, Marcelo, "La doctrina de los actos propios", Editorial Reus - B. de F., Madrid-Montevideo, 2005, en coautoría con el profesor Carlos ROGEL VIDE.
} 
los intereses de dos personas no brota de lo declarado por una y otra, puede brotar, no obstante, de la conducta de ambas en su recíproca influencia. Como un fundamental postulado de política jurídica, aparece una vez más la necesidad de proteger la confianza depositada en lo aparentado por la declaración. El problema de si ha de producir efectos una sola declaración de voluntad, debe resolverse -como todos los problemas jurídicossegún criterios de política jurídica que en este caso son los que aconsejan proteger dicha confianza»"3. Esta elaboración del maestro catalán, es calificada por CASTÁN como de excelente criterio, opinión que compartimos.

Vista bajo estos ojos, la declaración unilateral de voluntad adquiere en el derecho moderno una nueva importancia, una trascendencia mayor, que la eleva muy por encima del acotado rol que se le había reconocido otrora. Ya no puede sostenerse con seriedad que el rol de la declaración unilateral de voluntad se acota a unas pocas temáticas, bien valladas por cierto, ni que su funcionalidad sea dudosa.

A la luz de los desarrollos es posible que la declaración unilateral de voluntad sume nuevas aplicaciones en el derecho de habla castellana, adquiriendo una vigencia renovada, que le saque el olor a naftalina de las viejas disputas y de las remanidas críticas. Focalizaremos aquí el análisis de la confianza legítima, una de sus especies innominadas y de mayor futuro.

\section{2) La doctrina de la confianza legítima.}

Bajo la denominación de doctrina de la confianza legítima, de la confianza justificada o de la expectativa plausible se aplica crecientemente en el mundo -también en la doctrina y jurisprudencia argentina-, una doctrina paralela o complementaria a la de los actos propios, que busca cubrir los intersticios que ella deja expuestos a la volubilidad y a la malicia ${ }^{4}$ y que, a veces, se solapa con ella.

${ }^{3}$ CASTÁN TOBEÑAS, José, "Derecho civil español común y foral", $16^{a}$ edición, Edit. Reus, Madrid, 1992, tomo III, p. 112.

${ }^{4}$ Una autora ha propuesto cambiar el nombre de doctrina de la confianza legítima por el de doctrina de la expectativa plausible o de la expectativa justificada, expresiones mucho más cercanas a la utilizada en Inglaterra paa denominar a una idea equiparable a la que estamos analizando ("legitimate expectation") (RONDÓN de SANSÓ, Hildegard, "El principio de confianza legítima o expectativa plausible en el derecho venezolano", en "El derecho venezolano a finales del Siglo XX: ponencias venezolanas al XV Congreso Internacional de Derecho Comparado, Bristol, Inglaterra", Caracas, 1998, p. 
No se trata de una idea jurídica que tenga una prosapia milenaria; no tiene una historia ni siquiera centenaria como herramienta jurídica, pero sí ha tenido un enorme crecimiento en los últimos lustros.

Bien ha dicho un jurista colombiano contemporáneo que "la confianza como objeto de análisis es un tema que siempre ha concitado el interés de los estudiosos, lo cual explica la existencia de tantas investigaciones realizadas desde los más variados horizontes científicos. El derecho, en cuanto disciplina que busca contribuir al desarrollo normal de las relaciones interpersonales, no ha sido ni podía ser indiferente ante el tema, lo cual explica que desde tiempos inmemoriales la confianza haya sido objeto de protección jurídica. Si bien en la historia de las civilizaciones muchas de las instituciones del derecho han contribuido al amparo de la confianza, debemos admitir que su invocación expresa como principio del derecho público es relativamente reciente. En efecto, en el transcurso de los últimos años tanto en el foro como en la academia se ha venido hablando con progresiva insistencia del "principio de protección de la confianza legítima", cuyo sentido, alcances y proyecciones, además de curiosidad, interés y expectación, despiertan a su paso sentimientos encontrados de adhesión y de rechazo en algunos sectores de la crítica".

Para dar una primera aproximación a la idea, cabe decir con la Prof. RONDÓN DE SANSÓ que "con la noción de confianza legítima se alude a la situación de un sujeto dotado de una expectativa justificada de obtener de otro, una prestación, una abstención o una declaración favorable a sus intereses, derivada de la conducta de este último, en el sentido de fomentar tal expectativa. Si bien entre nosotros la relación que da lugar a la confianza legítima generalmente se plantea frente a la Administración, también puede surgir entre particulares, por lo cual no sería correcto limitar la noción expresada a la esfera del Derecho Administrativo, aún cuando el presente estudio esté dedicado casi por entero a ese ámbito"

315 y ss y en la página de internet de la Academia Nacional de Drecho y Ciencias Sociales de Córdoba, en http://www.acaderc.org.ar/doctrina/articulos/artconfianza-legitima).

${ }^{5}$ VALBUENA HERNÁNDEZ, Gabriel, "La defraudación de la confianza legítima. Aproximación crítica desde la teoría de la responsabilidad del Estado", $1^{a}$ edic., Edic. de la Universidad Externado de Colombia, Bogotá, 2008, Introducción.

${ }^{6}$ RONDÓN de SANSÓ, Hildegard, "El principio de confianza legítima o expectativa plausible en el derecho venezolano", en "El derecho venezolano a finales del Siglo XX : ponencias venezolanas al XV Congreso Internacional de Derecho Comparado, Bristol, Inglaterra”, Caracas, 1998, p. 311. 
El origen del principio de protección de la confianza legítima es ubicado, casi sin discusiones, en un espacio y un tiempo definidos: la República de Alemania Federal, en el período de posguerra ${ }^{7}$. Por ese motivo, la doctrina administrativa y las resoluciones judiciales alemanas (Corte Constitucional de Karlsruhe y Corte Administrativa Federal) fueron por muchos años fuentes exclusivas de obligada consulta en esta materia ${ }^{8}$.

El origen de esta doctrina suele ubicarse en un precedente fallado por el Tribunal Superior Administrativo de Berlín, con fecha 14 de noviembre de 1956, en el que se aplicó por primera vez el principio de confianza legítima ante la denegación de una pensión que se había prometido a la viuda de un funcionario alemán, a quien se le había asegurado que se le acordaría una pensión, si se mudaba del territorio de la Alemania controlada por los rusos a Berlín occidental. Mudada la viuda, con los gastos consiguientes, se pretendió denegarle el beneficio, mereciendo tal situación la aplicación de esta doctrina, para amparar la confianza legítima que se le había creado a la accionante ${ }^{9}$.

El profesor y ex camarista argentino Dr. Pedro COVIELLO escribió al respecto que "el principio (Vertrauensschutz, que en su textual traducción significa 'protección de la confianza', a la que luego se agregó en otras traducciones la palabra 'legítima') surgió en el derecho alemán, en donde adquirió talante constitucional, como una derivación del principio de seguridad jurídica (Rechtssicherheit), y se lo considera - junto con el último- como una de las consecuencias de los valores propios del Estado de Derecho" $" 10$.

Pese a que los orígenes de la idea se remontan a la doctrina germánica, la

${ }^{7}$ CALMES, Sylvia, «Du principe de la protection de la confiance légitime en droit allemand, communautaire et français », Edit. Dalloz, París, 2001, pp. 490 y ss.; BERNAL FANDIÑO, Mariana, «El deber de coherencia en los contratos y la regla del venire contra factum proprium», en «Int. Law: Rev. Colomb. Derecho Int. Ildi». Bogotá (Colombia) N 13, Noviembre de 2008, p. 311; VINCENT,.Pierre, "La Faible Impact du Principe de Confiance Légitime en Droit Administratif Français", París, en « Revue Française de Droit Administratif », N. ${ }^{\circ} 16$ (2), marzo-abril de 2000, pp. 254/265.

${ }^{8}$ BERNAL FANDIÑO, Mariana, «El deber de coherencia en los contratos y la regla del venire contra factum proprium», en «Int. Law: Rev. Colomb. Derecho Int. Ildi». Bogotá (Colombia) $\mathrm{N}^{\circ} 13$, Noviembre de 2008, p. 311; CORTÉS CAMPOS, Josefina, "Cambio regulatorio y seguridad jurídica, breves notas sobre el principio de confianza legítima", en la página de Internet de la Universidad de California, http://www.escholarship.org/uc/item/3h66p191?display=all\#page-1, pp. 1 у 2.

${ }^{9}$ BERNAL FANDIÑO, Mariana, «El deber de coherencia en los contratos y la regla del venire contra factum proprium», en «Int. Law: Rev. Colomb. Derecho Int.». Bogotá (Colombia) $\mathrm{N}^{\circ}$ 13, Noviembre de 2008, p. 311.

${ }^{10}$ COVIELLO, Pedro José Jorge, La confianza legítima, en revista El Derecho (ED) t. 177, pp. 894 y ss. 
herramienta de la confianza legítima actualmente posee importantes antecedentes doctrinales y jurisprudenciales en nuestro país y en el derecho europeo y comparado ${ }^{11}$.

Para comprender esta doctrina hay que alejar de la mente prejuicios de naturaleza dogmática y que nos fueron impuestos por nuestra formación clásica, la que capta en esta doctrina un fuerte e inmediato perfume exótico. Palabras más, palabras menos, así lo ha dicho un eminente magistrado de la Corte comunitaria europea, quien se ha referido a esta herramienta, diciendo que a pesar del perfume exótico que la rodea, la confianza legítima está llamada a despertar en los juristas el interés por su estudio, ya que su aplicación puede contribuir a la evolución del derecho ${ }^{12}$.

Dejando atrás el prejuicio, pero también teniendo prevención contra el exceso de entusiasmo, intentaremos seguidamente dar una breve pero clara visión de su funcionalidad y alcance.

\section{3) Fundamentos de la idea.}

No es difícil concluir prontamente que el núcleo de fundamentación de esta doctrina se alínea con la garantía de seguridad jurídica, al punto de ser ésta una especie o necesaria derivación de aquélla. En el derecho francés, el primer fallo que acoge esta herramienta data del 24 de Marzo de 2006, fecha en que el Consejo de Estado francés

${ }^{11}$ Puede verse un interesantísimo esudio comparativo del desarrollo de esta doctirna en diversos países, en VALBUENA HERNÁNDEZ, Gabriel, "La defraudación de la confianza legítima. Aproximación crítica desde la teoría de la responsabilidad del Estado", $1^{a}$ edic., cit, Capítulo II.- El principio de protección de la confianza legítima en el derecho nacional y comparado y en FAUVARQUECOSSON, Bénédicte, "La confiance légitime et l'estoppel", en "Electronic Journal of Comparative Law", vol. 11.3 (December 2007), en http://www.ejcl.org/113/article113-8.pdf, pp 1/40. Respecto del derecho inglés, puede verse SARMIENTO RAMÍREZ-ESCUDERO, Daniel,."El principio de confianza legítima en el derecho inglés: la evolución que continúa", Cizur Menor (Navarra), en "Revista Española de Derecho Administrativo", N. 114, Edit. Civitas, Madrid, 2002, pp. 233/262. Y en relación con el tema en el derecho francés, puede consultarse el aporte de MELLERAY Fabrice, "La revanche d'Emmanuel Lévy ? L'introduction du principe de protection de la confiance légitime en droit public français", en "Droit et société", 2004/1, N 56-57 pp 143 a 149.

12 PUISSOCHET, Jean Pierre, “Vous avez dit confiance légitime?”, en "Mélanges en I’honneur de Guy Braibant », Edit. Dalloz, París, 1996, pp. 581 y ss. 
receptara precedentes comunitarios, dejando particularmente en claro que la confianza legítima está atada con una cadena de acero al principio de seguridad jurídica ${ }^{13}$.

Agudamente se ha expuesto que "las razones que justifican la adopción del principio de confianza legítima son idénticas en todos los ordenamientos que lo han asumido. Se trata de una exigencia de la más elemental seguridad jurídica, y, a su vez, derivación del Estado de Derecho. Todo ciudadano tiene derecho a prever y ordenar pro futuro su trayectoria vital; a que el Derecho le garantice un mínimo de estabilidad sobre la cual constituir un proyecto personal o profesional, sin que los cambios del ordenamiento supongan trastornos en las relaciones jurídicas ya entabladas. Se trata de un imperativo jurídico plasmado en el artículo 1.1 y 9.3 del texto constitucional español, una exigencia del rule of law en el ordenamiento jurídico inglés, un elemento del État de droit francés y el Rechtsstaat alemán, y un principio del Derecho comunitario reconocido por el Tribunal de Justicia de las Comunidades Europeas. Puede afirmarse con seguridad que el valor detrás de la confianza legítima es lo suficientemente fuerte como para tener una extensión transnacional, y, a pesar de las diferencias en la articulación concreta del principio en cada ordenamiento, pensamos que la racionalidad interna del mismo es idéntica en el contexto jurídico occidental"14.

En un fallo argentino se sostuvo, en una senda no lejana a la anterior, que la seguridad jurídica es uno de los elementos fundamentales del principio del Estado de Derecho. Los ciudadanos tienen que ser capaz de prever posibles injerencias de parte del Estado que les pueden afectar y de comportarse de manera adecuada. Los individuos tienen que poder fiarse de que sus acciones que son lícitas bajo el derecho actual y de las que siguen determinadas consecuencias jurídicas también pueden ser consideradas lícitas en el futuro...Seguridad jurídica significa para el ciudadano en primer lugar la protección de la confianza legítima ${ }^{15}$.

\footnotetext{
${ }^{13}$ LE TOURNEAU, Philippe, «Droit de la responsabilité et des contrats », $8^{a}$ edic., Dalloz, París, 2010, No 205, p. 110.

14 SARMIENTO RAMÍREZ-ESCUDERO, Daniel,."El principio de confianza legítima en el derecho inglés: la evolución que continúa", Cizur Menor (Navarra), en "Revista Española de Derecho Administrativo", N. ${ }^{\circ} 114$, Edit. Civitas, Madrid, 2002, pp. 240 y ss..

${ }^{15}$ C. Nac. Cont. Adm. Fed., sala 4a , 5/7/01, Lagos Alcaino, María Teresa y otros v. Universidad de Buenos Aires (Resol. Cs 938/98)/Causa: 11.265/2000).
} 
Se agregó allí que el principio de la confianza legítima se erige en pieza clave en la limitación y el control del ejercicio de la potestad administrativa de volver sobre los propios actos (prólogo a la obra "La protección de confianza en el Derecho Administrativo", de Federico Castillo-Blanco). La actuación administrativa de un Estado de Derecho está (y debe estar) caracterizada en gran medida por la existencia y a la vez por la permanencia de un determinado status quo de reglas y decisiones fijas, que estimulan, dirigen y limitan la vida social y el comportamiento del individuo dentro de la sociedad ${ }^{16}$.

Y en otro fallo, el mismo tribunal dejó sentado que si tomamos como punto de partida los principios del Estado de Derecho, la buena fe o la equidad, sea que hagamos referencia a la "legitimate expectation", a la "vertrauensschutz", o a la confianza legítima, frente a la comprobación de la existencia de un comportamiento jurídicamente relevante de la Administración y de la afectación de intereses legítimos de los ciudadanos en razón de una variación de dicho comportamiento, no resultaría razonable considerar a la situación como indigna de protección por parte del orden jurídico ${ }^{17}$.

Pero la contribución que nos ha parecido de antología en lo que a expresar los fundamentos de esta teoria importa, es la contribución de un profesor francés, Fabrice MELLERAY, quien ha expuesto que "la cuestión de los fundamentos del principio de protección de la confianza legítima fue objeto de discusiones tan sabias como nutridas y permanece muy controvertida. Nos contentaremos aquí con presentar la tesis más corrientemente desarrollada. Ella puede ser resumida de la manera siguiente: el principio de protección de la confianza legítima es una de las facetas de la seguridad jurídica que en sí misma es un componente del Estado de derecho. Esta construcción, como una muñeca rusa, comprende así tres niveles: el principio de protección de la confianza legítima, su "fuente directa" (la seguridad jurídica) y su "fundamento lejano (El Estado de derecho del que la seguridad jurídica es un "componente elemental")"18.

\footnotetext{
${ }^{16}$ C. Nac. Cont. Adm. Fed., sala 4 ${ }^{\mathrm{a}}$, 5/7/01, Lagos Alcaino, María Teresa y otros v. Universidad de Buenos Aires (Resol. Cs 938/98)/Causa: 11.265/2000).

${ }^{17}$ C. Nac. Cont. Adm. Fed., sala 4a, 3/7/01, Bendomir, Jorge Pablo v. E.N. ( $\mathbf{M}^{\circ}$ de Economía) /Causa: 5.242/97, voto en disidencia del Dr. Galli.

18 MELLERAY, Fabrice, "La revanche d'Emmanuel Lévy? L'introduction du principe de protection de la confiance légitime en droit public français", en "Droit et société", 2004/1 - N 56-57, p. 147.
} 
Sigue diciendo MELLERAY, que "Esta genealogía jurídica del principio de protección de la confianza legítima es rica en enseñanzas en cuanto a los valores sobre los cuales reposa esta norma. Se trata claramente de un principio liberal e individualista. En efecto, tanto el Estado de derecho que la seguridad jurídica reposan sobre una axiología profundamente liberal (aunque a veces enturbiada o enmascarada) pretendiendo proteger a los individuos contra el Estado. Tal es lógicamente también el caso del principio de protección de la confianza legítima, que deriva de ellos" ${ }^{19}$.

En estas línea dice Sylvia CALMES que "la idea de protección de la confianza legítima, que expresa el deseo de seguridad del ciudadano, actúa como contrapeso destinado a fortificar la posición amenazada del individuo frente al poder creciente de las personas públicas, en la medida en que el deseo individual de estabilidad y de previsibilidad de la acción pública, causado por esta dependencia acrecentada, no puede ser saciado siempre por los medios de derecho conocidos por todos. El "principio de protección de la confianza legítima” apareció pues con vistas a limitar y a racionalizar el poder estatal, en interés del desarrollo libre del individuo"20.

Por último cuadra citar aquí la contribución de un administrativista chileno, Jorge BERMÚDEZ SOTO, quien ha expuesto que "una comprensión amplia de los principios de legalidad y seguridad jurídica puede servir también, incluso bajo nuestro ordenamiento, de base posible para asentar la vigencia de este principio. En virtud del principio de legalidad en su vertiente atributiva, le está vedado a la Administración Pública actuar en ejercicio de sus potestades de manera abusiva (arbitraria) o en exceso de poder. Es precisamente en el primer caso, el del abuso en el ejercicio de potestades, el de la arbitrariedad, comprendidos dentro del principio de legalidad en sentido amplio, en que la Administración deberá motivar y señalar las razones para su actuación. Si tal actuación supone una alteración en la interpretación de la norma o un cambio en la manera de regular o de resolver, solo estará legítimamente autorizada para hacerlo, si

\footnotetext{
${ }^{19}$ MELLERAY, F., "La revanche d'Emmanuel Lévy?... », cit, p. 148.

${ }^{20}$ CALMES, Sylvia, "Du principe de protection de la confiance légitime en droits allemand, communautaire et français”, Edit. Dalloz, París, 2001, p. 9.
} 
respeta, entre otros, la confianza que los administrados tienen en su forma o dirección de la actuación",21.

\section{4) Ambito de aplicación y materias a las que resulta aplicable la idea.}

La doctrina de la confianza legítima tiene un ámbito de aplicación colindante y a veces superpuesto con el de la doctrina de los actos propios. El riesgo de la superposición de territorios suele ser frecuente en el caso de doctrinas jurídicas creadas pretorianamente, como son ambas.

Es más, incluso un agudo jurista español como Luciano PAREJO ALFONSO, ha dicho que "el principio de la confianza legítima se erige en pieza clave en la limitación y el control del ejercicio de la potestad administrativa de volver sobre los propios $\operatorname{actos}^{, 22}$.

En este concepto, no quedan deslindados los campos de una y otra doctrina, al punto de que pareciera que la doctrina de la confianza legítima es una aplicación de la de los actos propios, pero acotada al segmento administrativo, lo cual no es del todo correcto $^{23}$. Ello, pues si bien la doctrina de la confianza legítima tiene un importante rol en derecho administrativo para impedir la volubilidad de los organismos estatales que quieran recortar o dejar sin efecto derechos o expectativas que los particulares venían teniendo, no se reduce a ese costado su territorio de aplicación, sino que desde el inicio de la idea en el "caso de la viuda de Berlín" su ámbito de aplicación se ha ido alongando, hasta cubrir otros terrenos que el de la volubilidad estatal.

Tampoco queda claro el deslinde de terrenos en un fallo de la Corte Constitucional de Colombia, donde se resolvió que el "principio constitucional de la confianza legítima", se fundamenta en los principios de la buena fe..., seguridad

21 BERMÚDEZ SOTO, Jorge, "El principio de confianza legítima en la actuación de la administración como límite a la potestad invalidatoria", en "Revista de Derecho" Vol. XVIII - N² Diciembre 2005, Valdivia, Chile, p. 85 y ss.

22 PAREJO ALFONSO, Luciano, prólogo a "La protección de la confianza en el Derecho Administrativo", de Federico Castillo-Blanco, Marcial Pons, Monografías Jurídicas, Madrid, 1998..

${ }^{23}$ Para analizar similitudes y diferencias de los actos propios (doctrina del stoppel en el commo law) y la de la confianza legítima, vid el interesantísimo artículo doctrinal de Bénédicte FAUVARQUECOSSON, titulado "La confiance légitime et l'estoppel", en "Electronic Journal of Comparative Law", vol. 11.3 (December 2007), en http://www.ejcl.org/113/article113-8.pdf, pp 1/20. 
jurídica ..., respeto al acto propio y adquiere una identidad propia en virtud de las especiales reglas que se imponen en la relación entre administración y administrado. Es, según la jurisprudencia de la Corte, éticamente deseable y jurídicamente exigible. Al respecto la Corte ha dicho que "Este principio, que fue desarrollado por la jurisprudencia alemana, recogido por el Tribunal Europeo de Justicia en la sentencia del 13 de julio de 1965, y aceptado por doctrina jurídica muy autorizada, pretende proteger al administrado y al ciudadano frente a cambios bruscos e intempestivos efectuados por las autoridades. Se trata entonces de situaciones en las cuales el administrado no tiene realmente un derecho adquirido, pues su posición jurídica es modificable por las autoridades. Sin embargo, si la persona tiene razones objetivas para confiar en la durabilidad de la regulación, y el cambio súbito de la misma altera de manera sensible su situación, entonces el principio de la confianza legítima la protege. En tales casos, en función de la buena fe (CP art. 83), el Estado debe proporcionar al afectado tiempo y medios que le permitan adaptarse a la nueva situación. Eso sucede, por ejemplo, cuando una autoridad decide súbitamente prohibir una actividad que antes se encontraba permitida, por cuanto en ese evento, es deber del Estado permitir que el afectado pueda enfrentar ese cambio de política" 24 .

Nos parece atinado lo expuesto por el Prof. Pedro COVIELLO acerca de que el principio de la confianza legítima busca la protección de aquellas situaciones jurídicas en las que por aplicación de la doctrina de los actos propios u otros institutos iusadministrativos o procesales no podría alcanzarse la solución justa del caso. El nexo que se puede encontrar con el estoppel y la doctrina de los propios actos es que existe un elemento común que es la confianza. Este principio impide que una de las partes cocontratantes realice actos posteriores que defrauden la confianza que su conducta anterior pueda haber generado en la otra parte, vinculándola a sus propios actos o prácticas anteriores ${ }^{25}$.

Y agrega el Prof. COVIELLO, que "la confianza legítima no actúa la mayoría de las veces en forma pura, sino que en la mayoría de los supuestos está acompañada de otras figuras jurídicas. En tal inteligencia, podría decirse que el sólo acudimiento a ella

${ }^{24}$ Corte Constitucional de Colombia, Sala $3^{\mathrm{a}}$, 2/4/02, Sentencia T-046/02, en La Ley Online, con votos positivos de los magistrados Manuel José CEPEDA ESPINOSA y Jaime CÓRDOBA TRIVIÑNO y disidencia del Dr. Rodrigo ESCOBAR GIL.

${ }^{25}$ COVIELLO, Pedro José Jorge, La confianza legítima, en ED, 177-894. 
constituiría la última ratio cuando los otros instrumentos juridicos no son eficaces para la solución justa del caso. También la confianza legítima puede vese como una forma de exigir el comportamiento ético de la Administración frente a los compromisos asumidos (que no solo lo son por vía contractual sino igualmente a través de sus actos y comportamientos) cuando perjudican a los administrados" 26 .

Las aplicaciones de esta herramienta son variadas y no puede preveerse por anticipado todo el ancho de su ámbito de aplicación. Acaso las pautas anteriormente expuestas lleven a su aplicación a nuevos supuestos que hoy no se visualizan. Pero lo que debe quedar claramente establecido es que si bien en un comienzo esta doctrina se aplicaba con exclusividad a comportamientos estatales, hoy ello ya no ocurre, si bien el ámbito administrativo ha sido el territorio más fértil en que se ha implantado esta doctrina.

Es indiscutible que "el principio de protección de la confianza legítima de los particulares en el ámbito del Derecho público limita la actividad del poder público, para impedir que éste destruya sin razón suficiente la confianza que su actuación haya podido crear en los ciudadanos sobre la estabilidad de una determinada situación jurídica" ${ }^{27}$.

Y también lo es que debiera existir algún mecanismo legal que protegiera al ciudadano para el caso de que las derogaciones o modificaciones normativas de derechos de que disfrutaba pudieran ser arbitrarias o irrazonables; pero "como lealmente, no existe una norma expresa que proteja al ciudadano ante esta situación, aunque sí cabría su defensa jurídica invocando vulneración del principio de confianza"28. Y, en este plano, la confianza legítima juega un rol fundamental en la apreciación jurídica de los actos normativos ${ }^{29}$.

${ }^{26}$ COVIELLO, Pedro José Jorge, La confianza legítima, en ED, 177-921.

${ }^{27}$ SANZ RUBIALES, Iñigo, "El principio de confianza legítima, limitador del poder normativo comunitario", en "Revista de Derecho Comunitario Europeo", Año 4, No 7, 2000 , pp. 91 y ss.

${ }^{28}$ GONZÁLEZ FERNÁNDEZ, Juan José, "Una aproximación a los principios de seguridad jurídica, buena fe y protección de la confianza legítima en derecho administrativo", en revista juridica online "Noticias Jurídicas", en http://noticias.juridicas.com/articulos/15Derecho\%20Administrativo/200504-3555121421051720.html, p. 5.

${ }^{29}$ SANZ RUBIALES, Iñigo, "El principio de confianza legítima, limitador del poder normativo comunitario", en "Revista de Derecho Comunitario Europeo", Año 4, No 7, 2000 , p. 93. 
De tal modo, el principio de confianza legítima no queda reducido a ser aplicado en las esferas del derecho económico ${ }^{30}$ o de la actuación administrativa, especialmente cuando ella interviene en la economía, aún cuando es un hecho que la mayor parte de los casos en que se la ha aplicado en Europa se dio en momentos en que se habían producido cambios normativos relevantes o se estaba en una fase aguda de intervención económica estatal ${ }^{31}$.

En palabras de la Prof. Hildegard RONDÓN de SANSÓ “...la confianza legítima abarca todas las disciplinas jurídicas, y el hecho de que jurisprudencialmente se haya manifestado a través de fallos que versan sobre compensaciones monetarias, primas de exportación y montos en materia de jubilación, en forma alguna significa que esté limitada a la actuación o a la intervención económica de los entes públicos. La reincidencia de una misma temática alude esencialmente al hecho de que es la Corte de Justicia de las Comunidades Europeas el tribunal que ha conocido la mayor cantidad de causas sobre la materia y, obviamente, su esfera de competencia gira en el ámbito señalado, lo cual no implica que la disciplina coresponda exclusivamente a tal esfera. Debemos señalar al efecto que, en el derecho civil, mucho antes de que se acuñase como una figura novedosa la confianza legítima, en el campo precontractual se estimaba que el nacimiento de expectativas en alguna de las partes puede ser generador de vínculos jurídicos. Igualmente, debemos recordar que en nuestro Código Civil de 1942, reformado en 1982, expresamente se consagra una sanción indemnizatoria por incumplimiento injustificado de una promesa matrimonial" 32 .

Y a tal punto esta doctrina viene ampliando su territorio original de surgimiento, para colonizar nuevos, que una autora ha propuesto su aplicación a las relaciones electrónicas entre dos partes que no se conocen personalmente, en el ámbito de la

\footnotetext{
${ }^{30}$ Bien se ha dicho que "el ámbito material «natural» de la aplicación del principio es, sobre todo, el derecho económico. La confianza legítima tiene especial relevancia para el desenvolvimiento de un ordenamiento jurídico basado en el libre mercado, en el que los operadores económicos - y, en general, todos los ciudadanos - necesitan un marco jurídico relativamente estable para poder proyectar, con alguna certeza, las diversas operaciones, compromisos e inversiones económicas" (SANZ RUBIALES, Iñigo, "El principio de confianza legítima, limitador del poder normativo comunitario", cit, p. 94)..

${ }^{31}$ RONDÓN de SANSÓ, Hildegard, "El principio de confianza legítima o expectativa plausible en el derecho venezolano", en "El derecho venezolano a finales del Siglo XX : ponencias venezolanas al XV Congreso Internacional de Derecho Comparado, Bristol, Inglaterra”, Caracas, 1998, p. 318.

${ }^{32}$ RONDÓN de SANSÓ, Hildegard, "El principio de confianza legítima o expectativa plausible en el derecho venezolano", cit, pp. 318 y ss.
} 
internet $^{33}$, al entender que "en un entorno donde los actores no están en presencia uno del otro, la confianza desempeña un papel importante importante" ${ }^{34}$.

\section{5) Los requisitos de aplicación de la doctrina de la confianza legítima.}

Habiendo visto su surgimiento y ámbito de aplicación, debemos ocuparnos ahora de determinar los presupuestos de aplicación de la herramienta; máxime cuando, como dijo el Prof. COVIELLO en su trabajo, ella constituye última ratio del ordenamiento ${ }^{35}$, lo que exige la adecuada definición de sus requisitos o presupuestos de aplicación.

Ellos son a nuestro juicio cinco; uno de naturaleza subjetiva, tres de esencia objetiva y uno mixto:

a) Los sujetos (primer presupuesto subjetivo): Para que una situación de confianza justificada o de confianza legítima se produzca y sea invocable, deben existir al menos dos sujetos, que son los dos polos de la relación que generara la confianza. Una aguda jurista de habla francesa, ha expuesto una idea interesante: suele mantenerse una idea de confianza establecida entre dos personas, pero debe verse la cuestión como una relación entre dos entidades jurídicas, el emisor y el destinatario de la confianza, cualquiera sea su naturaleza ${ }^{36}$. Con esa aclaración, cabe expresar que los sujetos de la relación de confianza legítima son:

a.1) El sujeto activo, que puede ser cualquiera que pretenda de otro la asunción de una conducta en determinado sentido. Respecto al sujeto activo, normalmente es un particular, pero es posible que el

33 CHASSIGNEUX, Cynthia, "La confiance, instrument de régulation des environnements électroniques", en "Revue de droit de l'Université de Sherbrooke", revista del 29 de Octubre de 2007. pp. 441 y ss y que se encuentra cargado tambièn en la página del "Centre de recherche en droit public", de la Université de Montréal, en http://www.crdp.umontreal.ca/docs/news_211.pdf, p. 1 y ss.

34 CHASSIGNEUX, Cynthia, "La confiance, instrument de régulation des environnements électroniques", cit, p. 441.

${ }^{35}$ COVIELLO, Pedro José Jorge, La confianza legítima, en ED, 177-921.

36 CHASSIGNEUX, C., "La confiance, instrument de régulation des environnements électroniques", cit, p. 454. 
mismo sea incluso un órgano u ente público que actúe frente a otro. Este tipo de actuación es cada vez más frecuente en el mundo y genera un conflicto interadministrativo público ${ }^{37} ; \mathrm{y}$

a.2) El sujeto pasivo de aplicación de la doctrina, es, generalmente, la Administración Pública, uno de sus organismos autárquicos, una sociedad de economía mixta, aunque en rigor puede serlo cualquier ente público, una universidad ${ }^{38}$, o incluso, un particular.

b) Un primer presupuesto objetivo, la existencia de una relación entre los sujetos enunciados en el numeral anterior, que permita el surgimiento de una confianza legítima, justificada o plausible y no culpable, ciega o torpe: La confianza no surge de la nada ni espontáneamente entre dos personas que, por caso, colisionan con sus automotores sin conocerse previamente. Hablar de generación de confianza en las relaciones instantáneas es casi una ocurrencia. Por ende, la confianza legítima, para ser admisible requiere de un relacionamiento o contacto previo de alguna entidad entre los sujetos activo y pasivo, pues de otro modo, no podrían esgrimirse la defraudación de ninguna confianza relevante, pues no la habría o sería el fruto de la candidez o el excesivo entusiasmo.

Posiblemente quien mejor ha descripto la naturaleza de esa relación previa es Cynthia CHASSIGNEUX, quien ha expresado que "la confianza es pues el signo de la enajenación, en la intersubjetividad y en el futuro, el devenir. Diciendo que la confianza es el fruto de un equilibrio, de interacciones, nosotros entendemos que la confianza puede provenir de relaciones durables, sostenidas, de la reputación, de las emociones, de

${ }^{37}$ RONDÓN de SANSÓ, Hildegard, "El principio de confianza legítima o expectativa plausible en el derecho venezolano", cit, p. 322.

${ }^{38}$ En un interesante fallo argentino se decidió que si los alumnos cumplieron los requisitos académicos que establecía el organismo administrativo regulador, el que se encontraba vigente a la fecha en que ingresaron a la Facultad de Medicina, no puede una resolución de fecha posterior imponerles nuevos recaudos, pues debe protegerse la confianza legítima de los estudiantes frente a la actuación anterior de la Administración (C. Nac. Cont. Adm. Fed., sala 2a , 9/4/02, Ferreyra, Marta N. y otro v. Universidad de Buenos Aires, en JA 2005-I-sintesis). 
los sentimientos... También ella puede inscribirse en el marco de redes sociales, o de relaciones contractuales. Desde entonces, estas interacciones no están forzosamente basadas en un cálculo como lo dan a entender ciertos autores, que consideran que el empleo de esta noción es deshonrada desde que la acción de entrar en una relación es sólo el resultado de un cálculo entre ganancias contadas y riesgos incurridos" ${ }^{39}$.

c) Un segundo presupuesto objetivo, el hecho generador de la confianza: Este requisito implica la exigencia de una conducta generadora de confianza legítima en la contraparte. Puede tratarse "de un "cambio normativo - en su variante de norma general o norma individualizada- que de manera sorpresiva, sin medidas transitorias, ni mecanismos de compensación, altera la estabilidad de concretas situaciones jurídicas y frustra expectativas jurídicas creadas hasta ese momento para su destinatario. Obsérvese que cuando se alega este principio el interesado aún no ha adquirido todavía un derecho (de lo contrario estaríamos frente a un supuesto de derechos adquiridos)"40.

Pero debe tratarse de un hecho con potencialidad de creación de confianza, al no ser predicable la generación de una confianza basada en la nada misma o en meras conjeturas o verdaderas cabriolas argumentales sobre un hecho que no tiene normalmente asignada la significación que pretendió darle la persona confiada, que luego pretende transmutarse en actora en un juicio en base a esa confianza excesiva suya.

Como bien dijo el Dr. Coviello en un voto suyo, "no existe una situación que merezca la protección jurídica que surge por aplicación de la doctrina de la responsabilidad del Estado por su actividad normativa lícita, por no configurarse en el caso un supuesto que haya dado nacimiento a una situación de legítima confianza por la actora, y en la medida que la toma de préstamos en moneda extranjera fue producto de una libre decisión empresaria, que, como toda toma de resolución, implica consecuencias que cada uno debe asumir y no trasladarlas a los otros. Eso es ni más ni

39 CHASSIGNEUX, C., "La confiance, instrument de régulation des environnements électroniques", cit, pp. 455/458.

${ }^{40}$ CORTÉS CAMPOS, Josefina, "Cambio regulatorio y seguridad jurídica, breves notas sobre el principio de confianza legítima”, en la página de Internet de la Universidad de California, http://www.escholarship.org/uc/item/3h66p191?display=all\#page-1, p. 5. 
menos que la asunción, en una economía de mercado -más allá de la cualificación que se pudiera hacer a la de aquella época-, del riesgo empresario. En el sub lite la empresa actora ha continuado desarrollando e incrementando su actividad económica pese a los perjuicios invocados, perjuicios que, ciertamente, no fue la única en el país que los sufrió, sino más bien, con distintos alcances, casi toda la comunidad"41.

La conducta generadora de confianza o conducta que crea "la expectativa es la posición asumida por el sujeto pasivo en el sentido de interpretar determinadas normas en un sentido específico; atribuirle o negarle consecuencias jurídicas a ciertos hechos; respetar situaciones preestablecidas; acogerse a la costumbre o usos de ciertas comunidades; darle un tratamiento específico a los sujetos que dependen de su esfera de competencia. En el ámbito de las relaciones entre particulares, la expectativa surge frecuentemente en las relaciones pre-contractuales, sobre todo en la conducta que puede hacer que se presuma la existencia de una promesa o compromiso preliminar. En el caso de los entes públicos $\mathrm{y}$, específicamente, de las administraciones, la conducta ha de ser constante y reiterada, al punto de conformar una situación estable y de presuponer su repetición indefinida en el tiempo cada vez que se hagan presentes los mismos supuestos" $" 42$.

\section{d) Un presupuesto mixto o estado de conciencia subjetivo-objetivo, que es el} estado de confianza legítima en el mantenimiento de una situación jurídica: Si bien es un estado de conciencia, por lo que inicialmente es subjetivo, al no equivaler a la confianza ciega, a la candidez o al desenfado de asumir, como seguras, meras posibilidades, también tiene un importante componente de objetividad. Por eso decimos que se trata de una presupuesto mixto o subjetivo-objetivo. Se trata de un estado de conciencia "verificable" u "objetivado", por llamarle de alguna manera, que descarte la alegre alegación de una inocencia rayana en lo naif.

${ }^{41}$ C. Nac. Cont. Adm. Fed., sala 1a , 22/4/97, TIM /Tecnología Integral Médica S.A.- v. Estado Nacional /Ministerio de Economía y Otro s/ proceso de conocimiento /causa: 12191/96).

${ }^{42}$ RONDÓN de SANSÓ, Hildegard, "El principio de confianza legítima o expectativa plausible en el derecho venezolano", cit, p. 325. 
Este presupuesto "lo constituye la confianza justificada del sujeto de derecho respecto de la estabilidad y la previsibilidad del marco jurídico vigente y de la aplicación que de él hagan los distintos operadores jurídicos institucionalizados" ${ }^{43}$.

Y bien se ha dicho que "...para evitar toda forma de abuso, el emisor de la confianza debe permanecer vigilante. La confianza no debe ser ciega. No debe parecer una firma en blanco concedida a su destinatario. Necesita pues una parte de objetividad. Así, adoptando una actitud objetiva, la persona que da su confianza conserva un sentido crítico que le permitirá retirar a ésta a cada momento. La confianza no es pues una cosa adquirida. Puede transformarse en desconfianza. Por lo tanto de ahí, ciertos autores describieron la confianza como "la condición de un equilibrio, ella hace la alianza, un equilibrio en una estabilidad que se quiere prolongar. La confianza testimonia también el estatuto de enajenación del sujeto, ella compromete el devenir, por lo que no hay devenir sin alteridad" 44 .

e) Un presupuesto o elemento causal o finalista: Se requiere de un marco de legalidad en que se inserte la situación que se pretende mantener estable, para invocarla ${ }^{45}$.

Es que, la confianza alegada no puede partir de la antijuridicidad en que se aposentara quien la invoca. No cabe proteger a través de esta herramienta situaciones jurídicas consolidadas en condiciones de absoluta y flagrante anomia.

${ }^{43}$ CORTÉS CAMPOS, Josefina, "Cambio regulatorio y seguridad jurídica, breves notas sobre el principio de confianza legítima”, en la página de Internet de la Universidad de California, http://www.escholarship.org/uc/item/3h66p191?display=all\#page-1, p. 4.

44 CHASSIGNEUX, Cynthia, "La confiance, instrument de régulation des environnements électroniques", cit, pp. 455/458.

${ }^{45}$ En esta línea se dijo en un par de inteligentes fallos nacionales que "la seguridad jurídica es uno de los elementos fundamentales del principio del Estado de Derecho. Por ello, los individuos pueden fiarse de que sus acciones que son lícitas bajo el derecho actual, serán consideradas lícitas en el futuro. La seguridad jurídica significa para el ciudadano, en primer lugar, la protección de la confianza legítima. El principio de la confianza legítima, se erige en pieza clave en la limitación y el control del ejercicio de la potestad administrativa. La actuación administrativa de un Estado de Derecho está (y debe estar) caracterizada por la existencia y a la vez por la permanencia de un determinado status quo de reglas y decisiones fijas, que estimulan, dirigen y limitan la vida social y el comportamiento del individuo dentro de la sociedad (cfr. CNFed. Contenciosoadministrativo, sala IV, "in re" "Lagos Alcaino, María Teresa y otros c/Universidad de Buenos Aires (resol. Cs 938/98)", Expte. N: 11.265/2000, sentencia del 5/07/01); ídem, sala II, 20/2/07, “García Fernández, Agustín M. c. Estado Nacional”, en La Ley Online, voto de la Dra. Garzón de Conte Grand). 
Ello no significa que el actor o sujeto activo necesariamente deba cumplir todos los requisitos legales al momento de acceder al beneficio que pretende mantener. De exigirse ello, esta doctrina no se aplicaría nunca, ya que o no tendría aplicación posible, cuando el actor no ha cumplido algún requisito legal o su invocación sería superflua cuando sí los ha cumplido, ya que le bastaría con invocar la ley que le adjudica determinada prerrogativa o beneficio. Pero, en tal caso, debe existir un error excusable en cabeza del sujeto activo que haya sido inducido a error por parte del sujeto pasivo de la doctrina, lo que bonifica su actuación y la hace merecedera de tutela.

Lo que queremos significar con que la invocación de esta doctrina no puede partir de la antijuridicidad es que el sujeto activo no debe haber provocado con dolo o alguna maquinación el error administrativo o de su contraparte, que luego pretende utilizar en su beneficio. Ello implica además que debe existir buena fe en el sujeto que invoca esta doctrina, pues ella no es el ámbito del relativismo moral más descarnado.

Resulta claro que la confianza o expectativa debe ser conforme con el ordenamiento jurídico ${ }^{46}$, en forma tal que no existan normas de orden público que se opongan a la satisfacción de la pretensión, lo que llevaría a calificarla de antijurídica o ilegítima, debiendo existir además buena fe en el sujeto activo.

Cabe recordar que se ha dicho que "pueden existir situaciones en las cuales una costumbre derogatoria constituya el origen de la expectativa, lo cual no elimina el valor de la misma si se dan los restantes elementos. Lo que sí consideramos necesarios es la actuación de buena fe en el actor, o por lo menos, la ausencia de dolo" ${ }^{47}$.

Habiendo enumerado los cinco presupuestos esenciales de aplicación de esta doctrina, cabe aclarar que para que exista una confianza suscitada que amerite la aplicación de esta herramienta, la misma debe surgir de la concurrencia o conjunción de los siguientes elementos, bastando la falta de uno solo para que la idea resulte inaplicable.

${ }^{46}$ CORTÉS CAMPOS, Josefina, "Cambio regulatorio y seguridad jurídica, breves notas sobre el principio de confianza legítima”, en la página de Internet de la Universidad de California, http://www.escholarship.org/uc/item/3h66p191?display=all\#page-1, pp. 14 y ss.

${ }^{47}$ RONDÓN de SANSÓ, Hildegard, "El principio de confianza legítima o expectativa plausible en el derecho venezolano", cit, p. 317. 


\section{6) Los efectos de su aplicación.}

La admisión de la aplicación de la doctrina a un caso habilita la procedencia de la acción promovida por el sujeto activo frente al sujeto pasivo. La pretensión del sujeto activo que alega la existencia de confianza legítima en su favor, en general pretende el mantenimiento de una situación jurídica en la que el peticionario se hallaba emplazado.

En esta línea se ha juzgado reiteradamente que el principio de protección de la confianza legítima de los ciudadanos en la observancia y el respeto de las situaciones jurídicas derivadas de la aplicación de normas válidas y vigentes ${ }^{48}$ permite mantener los efectos de determinadas situaciones, lo que se justifica por la salvaguarda que merece el particular que confió legítimamente en la estabilidad de la situación jurídica creada por la propia Administración ${ }^{49}$.

Claro que esa pretensión de estabilidad puede tener dos sentidos diferentes según las circunstancias del caso:

a) puede ser una pretensión innovativa; o

b) puede tratarse de una pretensión no innovativa.

Como esta doctrina siempre resulta aplicable ante un cambio de situación jurídica, como primera medida debe distinguirse si el cambio de situación ya se produjo o resulta inminente su producción. Pongamos el ejemplo de una persona que estuviera percibiendo una jubilación que se le ha acordado sin cumplir las condiciones legales para acceder al beneficio, sin culpa ni dolo de su parte. Si, al momento de dictarse sentencia en la acción que promueve ella ante la comunicación de que se le quitará la jubilación, ya se le ha interrumpido el beneficio, ella promoverá una pretensión innovativa, tendiente a volver el status jurídico suyo al momento anterior a ese acto de

48 T.S.J. Córdoba, en pleno: "Asociación Vecinal 'Leandro N. Alem' y Otros c. Municipalidad de Río Cuarto Acción Declarativa de Inconstitucionalidad", A.I. Nro. 18 del 15031999; Autos Nro. 31/1999 "Lloveras, Carlos E. c. Caja...", Nro. 49/1999 "Alberti, Húber Oscar y Otros c. Pcia. de Córdoba..."; Sent. Nro. 12/2004 "Dinosaurio S.A. ..."; T.S.J. Córdoba, Sala Contencioso Administrativa: Sentencias Nro. 108/1999 "Astrada, Blanca Susana...", Nro. 79/2000 "I.A.T.E. ...", Nro. 101/2001 "Figueroa, Justo...", Auto Nro. 164/2002 "Villagra y Cía. ..."; ídem, 14/10/05, "Aguas Cordobesas S.A. c. Provincia de Córdoba", en LLC 2006, p. 337).

49 Trib. Sup. Just. de Córdoba, sala Contadm., 14/10/05, “Aguas Cordobesas S.A. c. Provincia de Córdoba", en LLC 2006, p. 337, fallo liderado por el agudo voto del Dr. Domingo Juan Sesín e ídem, Sent. Nro. 117/2001 "Abrahin, Carlos Eduardo..."; Coviello, Pedro José Jorge, "La protección de la confianza del administrado, Derecho argentino y derecho comparado", Ed. Lexis Nexis, AbeledoPerrot, Buenos Aires 2004, pp. 391 y ss. 
cese del beneficio previsional. En cambio, si al momento de dictar sentencia sea porque la persona, conjuntamente con la demanda ha interpuesto una medida cautelar o por otra causa, no ha dejado todavía de percibir su jubilación, en ese caso, la pretensión será no innovativa, porque pretende el mantenimiento de una situación jurídica tal como está, es decir, sin modificaciones ${ }^{50}$.

Pero, luego de esta primera distinción, hay que efectuar otra, referente a cuál es concretamente el efecto de la procedencia de la acción basada en la confianza legítima.

En tal sentido, es fundamental recordar una aguda elaboración de la Prof. RONDÓN DE SANSÓ, quien sobre el particular ha expuesto que "ante todo, hay que distinguir si el alegato de la confianza legítima es esgrimido contra un organismo dotado de imperatividad, es decir, que dicte actos de autoridad sujetos a recursos de nulidad o si, por el contrario, este alegato es opuesto entre particulares.... La diferencia fundamental entre una y otra hipótesis estriba en que en la primera la pretensión fundamental del actor estaría dirigida a obtener la nulidad del acto, en cuanto que en el segundo supuesto no habría acto alguno que anular y la demanda se dirigiría a otros objetivos. De lo anterior emerge que en los casos en los cuales la confianza legítima se hace valer frente a un ente de autoridad capaz de dictar actos dotados de imperatividad, la pretensión del actor podría tener el siguiente contenido:

1.- Pretender la nulidad del acto dictado en violación a la confianza legítima que el organismo generara en su esfera subjetiva. A su vez, esta primera posibilidad podría discriminarse en los posibles y eventuales requerimientos que a continuación se enuncian: a) la nulidad total del acto, con eficacia ex tunc; b) la nulidad parcial del acto, con eficacia ex nunc; c) la revocatoria del acto, lo cual implica el cese de sus efectos hacia el futuro; d) la modificación del acto, esto es, el cambio de alguno de los elementos de sus dispositivos (monto, tiempo, ámbito, etc.); e) la conversión del acto, lo

${ }^{50}$ Cabe recordar, que en un caso con puntos de contacto con el del ejemplo, se dijo a través del voto del Dr. Coviello, que en cuestiones de índole previsional, la rigurosidad de los principios debe necesariamente ceder frente a la protección que merecen quienes de buena fe tuvieron la legítima confianza de la validez de su derecho a percibir el beneficio en la forma que la administración le determinó (C. Nac. Cont. Adm. Fed., sala 1ª 11/12/1998 -Estado Nacional /Gendarmería Nacional- v. Briganti Inés s/ personal militar y civil de las FFAA. y de Seg. /Causa: 2671/98, voto del Dr. Coviello, consid. V.2). 
que sería equivalente a su calificación en un sentido diferente a la originariamente efectuada.

2.- La pretensión de que la Administración sea condenada (acción condenatoria), en cualquiera de los sentidos a que a continuación se expresan: a) que se abstenga de actuar en determinada forma (non facere); b) la pretensión de que la Administración actúe en un sentido determinado (prestación de hacer o facere); c) la pretensión de la entrega de una cosa (pretensión de condena a un dare)" ${ }^{51}$.

Agrega luego la citada doctrinaria venezolana que, en cambio, "si las pretensiones fuesen deducidas frente a particulares, obviamente las mismas quedarían limitadas a las del grupo "2.-", es decir, habría una total exclusión de las del grupo "1" 52 .

No ingresaremos aquí en determinaciones complejas sobre los alcances y efectos de la nulidad en derecho administrativo, dado que ello excede notoriamente el radio de giro de esta contribución y el espacio con que contamos en este estudio ${ }^{53}$.

\section{7) La temática en un caso notable.}

Recientemente nos tocó resolver, actuando como Juez de Audiencia, un caso en que los temas que venimos analizando se plantearon de modo inusualmente claro, dando lugar a un pronunciamiento donde tanto quien escribe como el colega de Sala, echamos mano de estas ideas para resolver el diferendo. Creemos que el caso tiene interés suficiente como para referirlo aquí.

Se trataba de un extraño supuesto en que una sociedad comercial propietaria de unos terrenos rústicos, improductivos, ubicados sobre una frecuentada ruta, extendió un “permiso de uso" por diez años a otra empresa, autorizando a ésta para que instale y explote un lavadero de camiones y otras actividades anexas.

${ }^{51}$ RONDÓN de SANSÓ, Hildegard, "El principio de confianza legítima o expectativa plausible en el derecho venezolano", cit, pp. 355 y ss.

${ }^{52}$ RONDÓN de SANSÓ, Hildegard, "El principio de confianza legítima o expectativa plausible en el derecho venezolano", cit, pp. 356 y ss.

${ }^{53}$ En la bibliografía citada en este trabajo pueden encontrarse las respuestas a tales interrogantes, por lo que a su lectura remitimos. 
La "permisionaria" hizo inversiones en el lugar, levantó construcciones para ampliar las escasas e insuficientes que existían e instaló primero un lavadero de camiones y luego un restaurant que, contra todo pronóstico, produjo un importante resultado económico para el sitio. Allí comenzaron los inconvenientes entre ambas empresas, pues quien había otorgado el permiso, mucho antes de los dos años de darlo, y mucho antes de los diez años de su período predeterminado de duración, pretextando que se trataba de un permiso revocable, quiso dejarlo sin efecto, oponiéndose la otra empresa, alegando que se trataba de un comodato y que en consecuencia había que respetar el plazo de autorización que se le confiriera.

La cuestión fue resuelta insatisfactoriamente en primera instancia y ello motivó una apelación ante la Excma Cámara de Apelaciones de Trelew (Patagonia Argentina), Sala A, que integramos, la que resolvió en definitiva el caso, con cita de importantes juristas españoles como Domingo Bello Janeiro, Carlos de la Vega Benayas y José Antonio Alvarez-Caperochipi y con profusión de fallos del Tribunal Supremo de España $^{54}$.

Esclarecimos allí la diferencia entre comodato y precario, que en ocasiones puede ser sutil, así como señalamos la extrema facticidad de la materia que muchas veces brinda muestras paradigmáticas de situaciones atípicas que no encajan ni un uno ni en otro concepto típico.

$\mathrm{Y}$, siendo tal el caso, encuadramos la cuestión dentro de la doctrina de la confianza legítima, subtipo o subespecie de la declaración unilateral de voluntad, de esencia innominada o atípica.

Dijimos en ese voto, en cuanto aquí interesa, lo que sigue:

El derecho reconoce, en ciertos y determinados casos, valor jurídico a la escueta declaración de voluntad de una persona; dichas declaraciones de voluntad reciben el nombre de negocios jurídicos unilaterales.

${ }^{54}$ Cámara de Apelaciones de Trelew, Sala A, 13 de Noviembre de 2012, "Transporte Ceferino S.R.L. c/ Construcciones Tierras Patagónicas S.R.L. s/ Desalojo" (Expte. 261 - Año 2012 CAT), en sistema informático Eureka (http://eureka.juschubut.gov.ar). 
Obligación por voluntad unilateral es la que contrae quien emite una declaración en el sentido de querer obligarse hacia otro, que puede estar determinado o indeterminado al momento de efectuar la manifestación.

Cabe aclarar que la determinación de los sujetos vinculados es ineludible al momento del cumplimiento de la obligación -como respecto de todo vínculo obligacional-, pues la determinación perfecta de los sujetos obligacionales es un elemento esencial de validez obligacional, que es exigible siempre al momento de cumplimiento, aunque excepcionalmente pueda serlo también en el momento de constitución del vínculo o en un momento determinado, previo al cumplimiento.

Bien mirada la cuestión, toda figura jurídica que obligue a una persona a mantenerse fiel a una declaración de voluntad previamente efectuada constituye una especie del género declaración unilateral de voluntad, como son la doctrina de los actos propios, la de confianza legítima y otras que puedan pensarse en similar rango de actuación, como la doctrina de la apariencia, inclusive.

Se ha definido al compromiso unilateral como el acto jurídico que crea una obligación a cargo de una persona y por su sola voluntad (MAZEAUD, Henri, Léon \& Jean - CHABAS, François, Derecho Civil. Obligaciones, trad. Luis Andorno, Zavalía Edit, Bs. As., 1997, t. I, p. 444, № 359).

También puede él verse como un acto jurídico unilateral por el cual el agente se compromete a satisfacer una prestación a favor de quien realice el hecho impuesto como condición.

En nuestro concepto, siguiendo una aguda definición de la actualizadora de la clásica obra del maestro GUTIÉRREZ y GONZÁLEZ, Raquel CONTRERAS LÓPEZ, pensamos que declaración unilateral de voluntad "es la necesidad jurídica de mantenerse en actitud de cumplir voluntariamente una prestacion, de carácter patrimonial (pecuniaria o moral), a favor de un sujeto que eventualmente puede llegar a existir, o que existiendo eventualmente, puede llegar a aceptar" (CONTRERAS LÓPEZ, Raquel Sandra, adiciones a la obra de GUTIÉRREZ Y GONZÁLEZ, Ernesto, "Derecho de las obligaciones", 16 a edic., Edit. Porrúa, México, 2007, p. 445, No 486bis; en igual sentido, TRIGO REPRESAS, Félix - 
LÓPEZ MESA, Marcelo, “Tratado de la responsabilidad civil”, 2ª edic., Edit. La Ley, Buenos Aires, 2011, T. I, cap. 2).

La declaración unilateral de la voluntad, es el poder o imperio de la voluntad del deudor, para crear per se obligaciones a su cargo, las que son perfectamente válidas y exigibles; y ello, con anterioridad de la concurrencia de la voluntad del acreedor.

Siendo esto así, el apartamiento de su declaración por parte del manifestante, lo emplazará lógicamente como sujeto pasivo de un supuesto de responsabilidad civil, debiendo responder de los perjuicios ocasionados a quien confiara en su declaración.

Pudiera parecer, llegado este punto, que el tema que analizamos constituye una temática baldía, carente de efectos prácticos. Esto no es así en absoluto; por el contrario, algunas de las formas de manifestación de la voluntad unilateral, en los últimos años han adquirido una decisiva importancia, la que se acrecienta día a día. Y el caso que nos convoca cabe sin esfuerzo dentro de esta matriz obligacional.

En el caso que nos convocara, juzgamos que el "permiso de uso" glosado a la causa, había configurado una declaración unilateral de voluntad del emisor que, al establecer el plazo y modalidades de la relación que se establecía entre las partes, había generado una "confianza legítima" del aceptante, que llevó a éste a edificar en el terreno un restaurant y a mejorar las instalaciones del lavadero ya existente, la que debía ser protegida ${ }^{55}$.

Bajo la denominación de doctrina de la confianza legítima, de la confianza justificada o de la expectativa plausible se aplica crecientemente en el mundo también en la doctrina y jurisprudencia argentina-, una doctrina paralela o complementaria a la de los actos propios, que busca cubrir los intersticios que ella deja expuestos a la volubilidad y a la malicia y que, a veces, se solapa con ella.

${ }^{55}$ Cám. Apels. Trelew, Sala A, 13/11/2012, "Transporte Ceferino S.R.L. c/ Construcciones Tierras Patagónicas S.R.L. s/ Desalojo”, sistema informático Eureka (http://eureka.juschubut.gov.ar. 
La doctrina de la confianza legítima es una derivación directa del principio general de la buena fe, con lo que aplicable de oficio en las causas, justamente por la misión y facultad judicial de evitar abusos contra la buena fe en el proceso o fuera de él.

Espigamos luego en nuestro voto nuestros desarrollos relativos a la confianza legítima, que al ser ya explicitados supra, y ser enteramente coincidentes con los conceptos y presupuestos ya referidos supra, no los reiteraremos ahora, dándolos por reproducidos.

Agregamos después, en cuanto aquí interesa, en cuanto al segundo presupuesto objetivo, esto es, el hecho generador de la confianza, que la declaración unilateral de voluntad, suscripta por el socio Gerente de la empresa demandada encarnaba este segundo presupuesto objetivo, idóneo o eficaz para generar la confianza de la demandada, acerca del permiso de uso y de su plazo de vigencia.

Y en cuanto al último presupuesto, el elemento causal o finalista, indicamos que se requería de un marco de legalidad en que se inserte la situación que se pretende mantener estable, para invocarla.

Es que, la confianza alegada no puede partir de la antijuridicidad en que se aposentara quien la invoca. No cabe proteger a través de esta herramienta situaciones jurídicas consolidadas en condiciones de absoluta y flagrante anomia, que quien invoca la confianza no podía desconocer ab initio.

La invocación de esta doctrina no puede partir de la antijuridicidad es que el sujeto activo no debe haber provocado con dolo o alguna maquinación el error administrativo o de su contraparte, que luego pretende utilizar en su beneficio. Ello implica además que debe existir buena fe en el sujeto que invoca esta doctrina, pues ella no es el ámbito del relativismo moral más descarnado.

En el caso que nos ocupara, la legalidad del actuar de ambos sujetos procesales era irreprochable: la concesión y aceptación de un permiso de uso de un predio del concedente, para destinarlo a una explotación lícita, autorizada por el 
Municipio, a través de habilitaciones específicas, muestra una absoluta regularidad jurídica, con lo que se cumplen en el caso, los cinco presupuestos o requisitos de la doctrina de la confianza legítima.

Resulta claro que la confianza o expectativa debe ser conforme con el ordenamiento jurídico, en forma tal que no existan normas de orden público que se opongan a la satisfacción de la pretensión, lo que llevaría a calificarla de antijurídica o ilegítima, debiendo existir además buena fe en el sujeto activo. En el caso que nos ocupa no las hay, por lo que la legalidad de la relación jurídica de las partes es indudable.

Para que exista una confianza suscitada que amerite la aplicación de esta herramienta, la misma debe surgir de la concurrencia o conjunción de los elementos o requisitos ya señalados, bastando la falta de uno solo para que la idea resulte inaplicable. En el caso que nos ocupa se reúnen todos y cada uno de ellos, no faltando ninguno, lo que abre la puerta a la aplicación de tal doctrina al sub lite.

La admisión de la aplicación de la doctrina a un caso habilita la procedencia de la acción promovida por el sujeto activo frente al sujeto pasivo. La pretensión del sujeto activo que alega la existencia de confianza legítima en su favor, en general pretende el mantenimiento de una situación jurídica en la que el peticionario se hallaba emplazado.

El efecto que la doctrina de la confianza legítima, derivación directa del principio general de la buena fe, protege la confianza legítima del accionado de autos, basada en la declaración unilateral de voluntad de fs. 37, dando causa al mantenimiento de la tenencia del terreno dado en uso a su parte.

Dijimos luego que otorgar un permiso de uso de un inmueble por diez años a un permisionario de uso y luego, sin causa admisible alguna probada $-\mathrm{y}$ sin invocar incluso alguna procedente- pretender revocar el permiso intempestivamente y en forma abrupta, vulnera el principio general de la buena fe, poniendo al concedente en franca contravención a las exigencias de esa manda, lo que es improcedente convalidar, por lo que procede rechazar su pretensión, que se aprecia violatoria del principio general de la buena fe, verdadero eje de nuestro 
sistema normativo, el que esta Sala ha hecho valer -incluso de oficio- en numerosos decisorios.

Añadimos después, con cita del maestro Carlos DE LA VEGA BENAYAS, que "el Código civil es claro al decir que los derechos deberán ejercitarse conforme a las exigencias de la buena fe. Formula aquí, en forma de mandato, un postulado de ética social, un deber de comportamiento conforme a la moral social imperante, vigente. Un postulado de moral general que, al interferir en las relaciones jurídicas, adopta la formulación de un principio general de Derecho, el de la buena fe, aplicado según las reglas de la tópica, es decir, conforme a las exigencias del caso o problema y a la concurrencia en él de circunstancias morales o de la ética imperante: honradez, rectitud, diligencia, ausencia de dolo o mala fe, cooperación, consideración del prójimo, como «topoi» reguladores o informadores" (DE LA VEGA BENAYAS, Carlos, "Teoría, aplicación y eficacia en las normas del Código Civil”, Edit. Cívitas, Madrid, 1976, p. 249).

La buena fe es una regla de conducta "que exige a las personas de derecho una lealtad y una honestidad que excluya toda intención maliciosa. Es una norma de comportamiento que debería ser apreciada in abstracto; es una buena fe-lealtad que el derecho positivo impone en las relaciones contractuales y extracontractuales" (IVON LOUSSOUARN, M., La buena fe, en "Tratado de la buena fe en el derecho", Edit. La Ley, Buenos Aires, 2004, T. II, p. 9).

La buena fe implica, entonces, una serie de obligaciones, que se tornan exigibles, según las circunstancias y naturaleza de la actuación del sujeto; el principio general de la buena fe siempre exige una actuación honesta, bienintencionada, no innecesariamente dañosa, no dada a dobleces ni contramarchas.

Es que, el principio general de la buena fe es una exigencia insustituible, incanjeable e infungible de toda pretensión en derecho. Nadie puede hacer valer pretensiones sin este recaudo. Ningún segmento ni ningún plano del ordenamiento 
jurídico argentino escapa del principio general que receptara el art. 1198 del Código Civil argentino, en su reforma de 1968.

Y no actúa de buena fe quien primero confiere una autorización amplia, con un largo plazo de vigencia a otro y luego, sin sucesión de continuidad y sin dar razones admisibles para el cambio de actitud, pretende revocar esa autorización, predicando su carácter precario y exigiendo el inmediato reintegro del bien. Una conducta así contraviene la confianza que la concesión del permiso había generado en la contraparte, afectando ilegítimamente los intereses de ésta.

A tenor de esos fundamentos, propusimos condenar al declarante a permanecer atado a su declaración por el plazo señalado en el permiso de uso.

El voto del Dr. Carlos A. Velázquez, que integra Sala con nosotros, siguió pareja senda.

Pudo verse de lo expuesto hasta aquí que la doctrina de la confianza legítima, así como su género, el de la declaración unilateral de voluntad, constituyen herramientas útiles, que en manos diestras pueden encontrar fácilmente asuntos a que aplicarse con ventaja respecto de otras elaboraciones.

\section{8) Corolarios.}

En lo que al objeto de este artículo concierne, es dable expresar que pudo verse hasta aquí que, en la medida en que la Administración o incluso un particular, puede ser obligado a mantenerse dentro del margen legítimo de confianza que sus declaraciones o su accionar previo fundadamente o legítimamente generaron en un tercero, es esta una herramienta que bien puede ubicarse dentro del ancho campo de la declaración unilateral de voluntad, como lo postulan PUIG BRUTAU y CASTÁN TOBEÑAS.

Tiene la figura un importante campo de acción en el derecho actual, en el que la confianza es un elemento de primera magnitud, tanto en el derecho como fuera de él; su anverso, la falta de confianza ha generado resultados desastrosos, tales como la quiebra 
de empresas, la existencia de corridas bancarias o cambiarias, la caída de funcionarios de su sitial o, incluso, el cese de gobiernos, etc.

El mundo globalizado de nuestros días ha mostrado acabadamente que buena parte del progreso económico de las empresas y de los países se basan en la callada y quieta confianza de los particulares y de las empresas. Cuando se desata un episodio de falta de confianza, suele crearse un pandemonium, que termina con enormes pérdidas económicas y graves consecuencias sociales.

Proteger la confianza legítima pero, a la vez, impedir que se entronicen en el imaginario popular y ciudadano manipulaciones capciosas, generadoras de una confianza artificial o que los cándidos o los pícaros esgriman supuestas situaciones de confianza que no sean dignas de tutela, deben ser las líneas directrices del accionar del moderno derecho.

La confianza tutelable, entonces, no es compatible con una contabilidad creativa pero torpemente llevada, ni con la manipulación de la opinión pública, pero tampoco con la excesiva candidez o la torpeza de los dañados, que no pueden pretender revertir su incuria sobre otros, basados en su falta de toma de recaudos mínimos exigibles.

Cuando la confianza es genuina y ha quedado antijurídicamente comprometida, debe ser tutelada por el derecho, pues en el fondo esta protección es una especificación del principio general de la buena fe a este tipo de supuestos. 